\title{
Analysis of Molar Substitution of Hydroxybutyl Group by Zeisel Reaction in Starch Ethers
}

\author{
Xiao-Lei Man ${ }^{1}$, Wei-Kang Peng ${ }^{2}$, Jun Chen ${ }^{3}$ and Xue-Li Liu ${ }^{2,4, *}$ \\ 1 Geosynthetics Applied Research Centre, College of Civil and Architecture Engineering, Chuzhou University, \\ Chuzhou 239012, China; manxl@hhu.edu.cn \\ 2 College of Material and Chemical Engineering, Chuzhou University, Chuzhou 239012, China; \\ pwkkk68@163.com \\ 3 College of Biotechnology and Pharmaceutical Engineering, West Anhui University, Lu'an 237012, China; \\ jun.chen06@rainbowfish11000.com \\ 4 School of Chemistry \& Chemical Engineering, Anhui University, Hefei 230601, China \\ * Correspondence: n_xueli@chzu.edu.cn
}

check for

updates

Citation: Man, X.-L.; Peng, W.-K.; Chen, J.; Liu, X.-L. Analysis of Molar Substitution of Hydroxybutyl Group by Zeisel Reaction in Starch Ethers. Molecules 2021, 26, 5509. https:// doi.org/10.3390/molecules26185509

Academic Editors: Stefan Janecek and Drago Šubarić

Received: 20 August 2021

Accepted: 9 September 2021

Published: 11 September 2021

Publisher's Note: MDPI stays neutral with regard to jurisdictional claims in published maps and institutional affiliations.

Copyright: (c) 2021 by the authors. Licensee MDPI, Basel, Switzerland. This article is an open access article distributed under the terms and conditions of the Creative Commons Attribution (CC BY) license (https:/ / creativecommons.org/licenses/by/ $4.0 /)$.

\begin{abstract}
A new etherified starch, $\delta$-hydroxybutyl starch ( $\delta$-HBS), was prepared by utilising 4chlorobutan-1-ol as the etherifying reagent. The method of Zeisel gas chromatography for the determination of the molar substitution was described. This technique offers a simple and rapid method for quantitative analysis with reproducible results. Meanwhile, the mechanism of the Zeisel reaction was also investigated.
\end{abstract}

Keywords: $\delta$-hydroxybutyl starch; molar substitution; Zeisel gas chromatography; mechanism

\section{Introduction}

The increasing industrial importance of hydroxyalkyl starch has created interest in methods for its analysis. Depending on the reaction conditions, the complex substitution pattern differs with respect to DS and MS, and regioselectivity. Among them, the molar degree of substitution (MS) values, i.e., the average number of hydroxyalkyl groups substituted per anhydroglucose unit, directly influence the physicochemical properties [1-5], and convenient methods for its determination have therefore become necessary.

Several analytical methods have been developed over the years for the determination of the molar substitution ratio of hydroxyalkyl starch. Zeisel gas chromatography has been employed as an analytical technique for the determination of the hydroxyethyl group in hydroxyethyl starch with the quantitative conversion of the substituted alkoxyl unit to the corresponding iodide by reaction with hydriodic acid [6-9], this technique offers a simple and rapid method for quantitative analysis with reproducible results. Cobler and Samsel [10] and Hodges [11] have analysed the determination of several alkoxyl substitutions in cellulose ethers by gas chromatography; for hydroxypropyl starch, the spectrophotometric (colourimetric) method of Johnson [12,13] is used to determine hydroxypropyl group content and is an official method of the Joint FAO/WHO Expert Committee on Food Additives [1]. Beyond that, Harry-O'Kuru [14] reported a modification of this colourimetric technique for the estimation of the MS of 2-hydroxybutyl starch ether whose preparation was etherified by reaction with epoxybutane [15-18]. The method involves hydrolysis of the 2-hydroxybutyl group to 1,2-butanediol which in turn is dehydrated to n-butyraldehyde and the enolic form of butenol. The simplicity, low cost, and accuracy of the procedure make it attractive as a routine procedure for industrial application.

In recent years, synthesis and characterisation of 2-hydroxybutyl starch have been studied, but there is no similar report on $\delta$-hydroxybutyl starch $(\delta$-HBS), i.e., the hydroxyl group in the terminal of butyl (Scheme S1, Figure 1). Meanwhile, in view of the importance of MS to the physicochemical properties, the present article describes the preparation of a new $\delta$-hydroxybutyl starch and develops a procedure for the analysis of the molar 
degree of substitution of $\delta$-HBS. In our initial studies, we have established a method for the determination of $\gamma$-HPS [19]. Owning to the difference in chemical structure and method applicability [20], we found that the method of spectrophotometry was not suitable to $\delta$-HBS. Thus, we herein report a modification of Zeisel gas chromatography for the estimation of the MS of $\delta$-hydroxybutyl starch ethers.

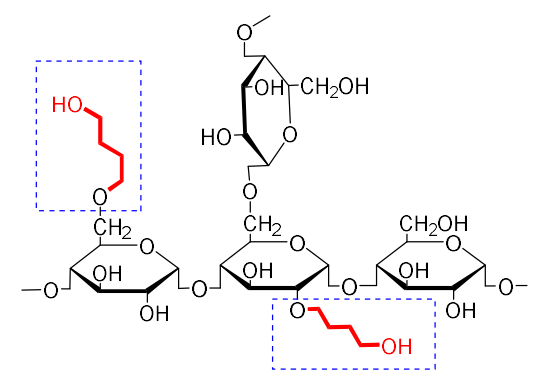

Figure 1. Chemical structure of $\delta$-hydroxybutyl starch.

\section{Experimental}

\subsection{Materials}

Corn starch, $\delta$-hydroxybutyl starch (made in a lab by ourselves), 1 -iodobutane, 2 iodobutane, toluene, o-xylene, hydriodic acid (55\%), tetrahydrofuran, 1, 4-butanediol (all analytical grade) were obtained from Aladdin Industrial Corporation, Shanghai, China.

\subsection{Method}

The gas chromatography (G5, puri general instrument Co., Ltd., Beijing, China) was equipped with an FID detector, and the capillary chromatographic column was SPB-5 $(30 \mathrm{~m} \times 0.32 \mathrm{~mm} \times 0.25 \mu \mathrm{m})$. The GC operating condition was as follows: The injector was held at $200{ }^{\circ} \mathrm{C}$, and the initial oven temperature of $60^{\circ} \mathrm{C}$ was held for $4 \mathrm{~min}$, which was then increased to $230^{\circ} \mathrm{C}$ at $30^{\circ} \mathrm{C} / \mathrm{min}$. This temperature was also held for $4 \mathrm{~min}$. The injection volume was $2 \mu \mathrm{L}$. The detector temperature was $250^{\circ} \mathrm{C}$.

Iodobutane, toluene, o-xylene were used for GC blank analysis, respectively. Toluene was used as the internal standard. Toluene of $1.0 \mathrm{~mL}$ was dissolved in o-xylene and made into a $200 \mathrm{~mL}$ solution in a volumetric flask. A set of standards was prepared by injecting $1,2,3,6,10,18,28$, and $40 \mu \mathrm{L}$ of iodobutane into test tubes stoppered with Suba Seals containing $2.0 \mathrm{~mL}$ of internal standard solution. The tubes were mixed and shaken vigorously and then allowed to stand for $10 \mathrm{~min}$. The exact weight of iodobutane was recorded. Each solution was used for GC analysis.

Approximately $50 \mathrm{mg}$ of $\delta$-hydroxybutyl starch or unmodified starch, accurately weighed, was transferred to a $25 \mathrm{~mL}$ reactive vial containing $200-250 \mathrm{mg}$ of adipic acid. Two millilitres of internal standard solution and $5 \mathrm{~mL}$ of hydriodic acid were added to the vial, which was immediately tightly capped with a Mininert valve and weighed. Vials were placed in a preheated block at $140^{\circ} \mathrm{C}$ for $10 \mathrm{~h}$. After being heated, the vials were removed from the block, shaken, cooled to room temperature, and reweighed to determine if any loss due to leakage had occurred. Then, $0.1 \mathrm{~mL}$ of the upper organic layer was transferred to a sampler vial containing $1.0 \mathrm{~mL}$ of o-xylene. The sampler vial was capped tightly and mixed for $5 \mathrm{~s}$. The obtained sample would be used for GC analysis.

\subsection{Calibration}

Calculation of the MS of hydroxybutyl starch is historically based on the butyl oxide unit, $\mathrm{C} 4 \mathrm{H} 8 \mathrm{O}$. The MS ratio, which is defined as the mole fraction of epoxybutane per anhydroglucose unit, is calculated by the following equations:

$$
W_{p}=\frac{72.11 \times P \times 100}{184.02 \times m} ; \mathrm{MS}=\frac{W_{p}}{100-W_{p}} \times \frac{162.14}{72.11}
$$


The $P$ in formula 1 equals the weight of iodobutane and $m$ equals the weight of sample; the values 184.02 and 72.11 in equations equal the molecular weight of iodobutane and $\mathrm{C} 4 \mathrm{H} 8 \mathrm{O}$, and 162.14 equals the molecular weight of anhydroglucose.

Based on the percent alkoxyl substitution anticipated in the prepared samples, the quantity of respective 2-iodobutane needed for calibration was determined according to the graph in Figure 2. The solutions were analysed by GC for obtained the relative calibration factor between 2-iodobutane and toluene. The calibration curve for butyl iodide in o-xylene ranging in concentration from 1.3 to $58.1 \mathrm{mg} / \mathrm{mL}$ was constructed. Relationship of $m_{\mathrm{C} 4 \mathrm{H} 9 \mathrm{I}} / m_{\text {Toluene }}$ to $A_{\mathrm{C} 4 \mathrm{H} 9 \mathrm{I}} / A_{\text {Toluene }}$ is shown in Figure 2. $m_{\mathrm{C} 4 \mathrm{H9I}} / m_{\text {Toluene }}$ is in direct proportion to $A_{\mathrm{C} 4 \mathrm{H} 9 \mathrm{I}} / A_{\text {Toluene, }}$ and the curve almost goes through the zero point. Statistical analysis of the calibration data was performed. All the data points fell on the same calibration line, which had a correlation coefficient of 0.9998. By linear regression, an equation for the calibration curve obtained is as follows:

$$
y=0.0453 x-0.0008, R=0.9998
$$

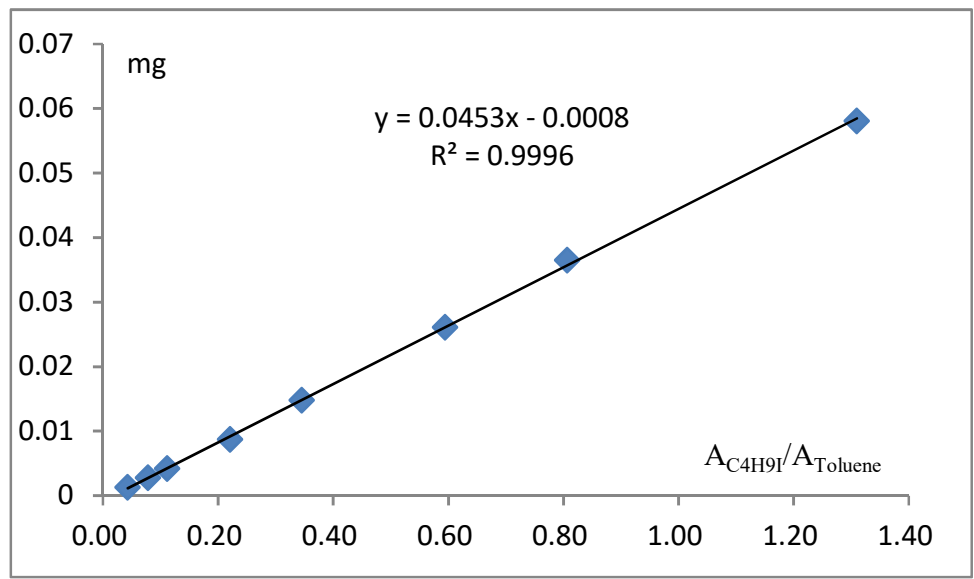

Figure 2. The linear curve of reference substance of 2-iodobutane.

The repeatability, linear range, and detection limits were studied for the GC method. The RSD for six replicate runs was $1.11 \%(n=6)$, which indicates that the method is sufficiently precise.

\section{Results and Discussion}

\subsection{Process and Mechanism}

The classical Zeisel distillation method utilises adipic acid to catalyse the hydriodic acid cleavage of the substituted alkoxyl groups quantitatively to their corresponding alkyliodides. Different from the cleavage of hydroxypropyl and hydroxyethyl starch $[7,9,21]$ (Figure 3) or cellulose ethers [11], the procedure of displacement reaction of 4-hydroxybutyl starch ether was slightly complicated (Figure 4). The final reaction products have two parts-namely, 1iodobutane and 2-iodobutane (Figure 5 and Figures S3-S6). The latter is the major reaction product. As it is mentioned in the mechanism, the first generated diiodo intermediate (i) proceeds through two routes to the desired alkyl iodide. One is acid catalysed and the direct conversion to 1-iodobutane (a) which can be converted to 2-iodobutane (b) by a succession of elimination and addition reaction. Another is the quantitative conversion of alkoxyl unit to butadiene which would be converted to the final 2-iodobutane (b). This conversion proceeds through a postulated vicinal 2,3-diiodo intermediate (ii). Each route can lead to the generation of 2-iodobutane (b). 


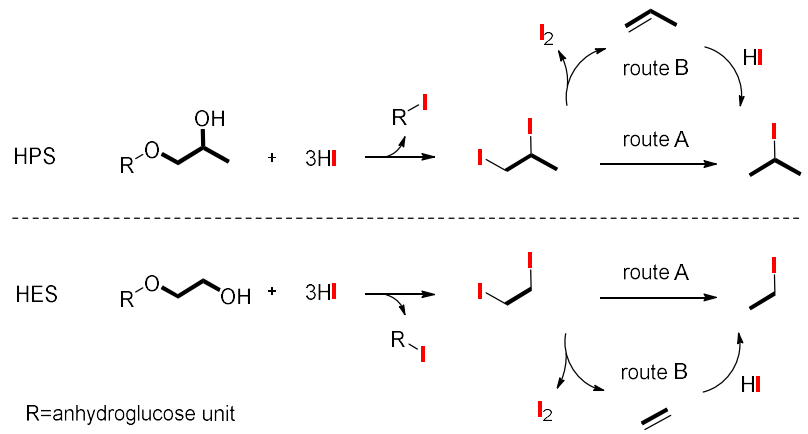

Figure 3. Proposed mechanism for the hydriodic acid decomposition procedure of HPS and HES.

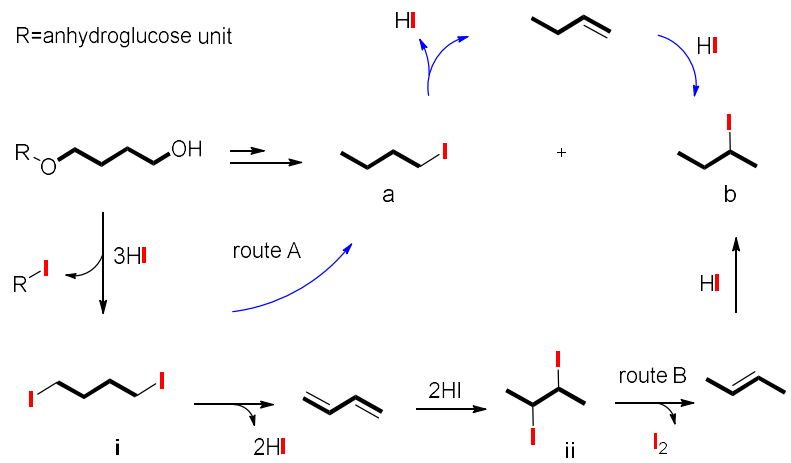

Figure 4. Proposed mechanism of iodobutane generation from $\delta$-HBS. (R=anhydroglucose unit).

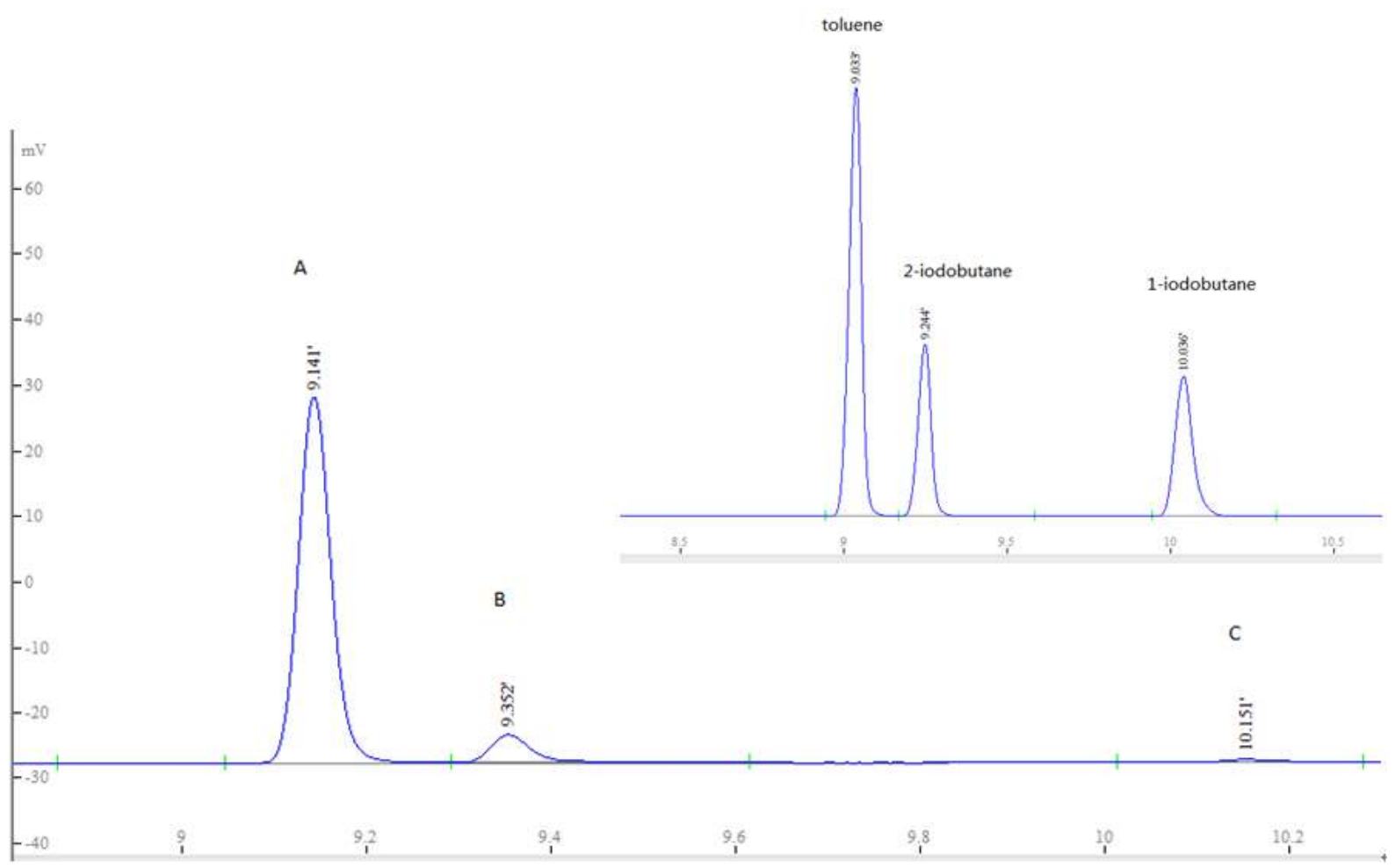

Figure 5. Chromatogram of extracts of the upper (o-xylene) layer of the reaction solution: (A) toluene; (B) 2-iodobutane; (C) 1-iodobutane.

To gain more insights into the reaction mechanism, a few control reactions were conducted. As shown in Table 1, support for this mechanism was obtained by heating 
tetrahydrofuran, 1,4-butanediol, in the presence of hydroiodic acid with o-xylene being present (entry 1-2). The result indicated that 2-iodobutane is the main hydrolysis product. Even then, there is still a little vestigial 1-iodobutane in the reaction mixture, and the peak area ratio of 2-iodobutane/1-iodobutane is 48.9:1 and 49.1:1. The exact quantity of the final product can be calculated by gathering 1- and 2-iodobutane. The relative error of the observed means was approximately $4.3 \%$ and $4.5 \%$. Meanwhile, 1 -iodobutane was also investigated (entry 3-5). Under the same catalytic system, 1- and 2-iodopropane were detected by chromatographing, and it was observed that after $24 \mathrm{~h}$, the conversion of reaction can reach up to $50 \%$. In addition, the gas chromatographic analysis was very rapid, with complete resolution of all peaks within a total retention time of less than $11 \mathrm{~min}$.

Table 1. Control experiments.

\begin{tabular}{|c|c|c|c|c|c|}
\hline Entry & Sample ${ }^{[a]}$ & Amt Added ${ }^{[b]} / \mathrm{mg}$ & $a^{[c]} / m g$ & $b^{[d]} / m g$ & $\begin{array}{l}\text { Theoretical } \\
\text { Weight }{ }^{[\mathrm{e}]} / \mathrm{mg}\end{array}$ \\
\hline 1 & tetrahydrofuran & 32.6 & 1.59 & 78.00 & 83.19 \\
\hline 2 & 1,4-butanediol & 25.1 & 0.98 & 47.93 & 51.25 \\
\hline 3 & 1-iodobutane & 40.1 & 27.63 & 10.83 & 40.1 \\
\hline $4^{[\mathrm{f}]}$ & 1-iodobutane & 27.8 & 24.70 & 1.58 & 27.8 \\
\hline $\left.5^{[g]}\right]$ & 1-iodobutane & 37.5 & 18.44 & 17.60 & 37.5 \\
\hline
\end{tabular}

[a] Unless otherwise stated, the hydriodic acid cleavage reaction condition: $1 \mathrm{~mL}$ internal standard solution, $2 \mathrm{~mL}$ hydriodic acid (55-58\%), $200 \mathrm{mg}$ adipic acid, $140^{\circ} \mathrm{C}$ for $12 \mathrm{~h}$; ${ }^{[b]}$ the mass of sample; ${ }^{[c]}$ the experimental values of 1 -iodobutane(a); ${ }^{[\mathrm{d}]}$ the experimental values of 2-iodobutane (b); ${ }^{[\mathrm{e}]}$ the theoretical weight of iodobutane; ${ }^{[\mathrm{f}]}$ for $6 \mathrm{~h}$; ${ }^{[g]}$ for $24 \mathrm{~h}$.

\subsection{Method Application}

The results of analysing three samples of hydroxybutyl starches containing significantly different amounts of hydroxybutyl substitution by the Zeisel-GC technique are shown in Table 2 and Table S1. The molar substitution increased as the volume of etherifying agent added to the reaction mixture increased, while other parameters were kept constant. This observation is consistent with increases in the MS with corresponding increases in the volume of the etherifying agent in the hydroxypropylation of starches [22-24].

Table 2. Determination of butoxy groups in hydroxybutyl starch ether.

\begin{tabular}{ccccc}
\hline Sample ${ }^{[\mathbf{a}]}$ & $\begin{array}{c}\text { Amt Added } \\
{[\mathbf{b}] \mathbf{m g}}\end{array}$ & $\begin{array}{c}\text { Peak Area Ratio } \\
{[\mathbf{c}]}\end{array}$ & $\begin{array}{c}\text { Observed/mg } \\
{[\mathbf{d}]}\end{array}$ & MS [e] \\
\hline 1 & 58 & 0.078 & 2.74 & 0.042 \\
2 & 51 & 0.112 & 4.26 & 0.076 \\
3 & 56 & 0.177 & 7.24 & 0.120 \\
\hline
\end{tabular}

[a] In-house synthesised $\delta$-hydroxybutyl starch ether; unless otherwise stated, the reaction was carried out in $50 \mathrm{~mL}$ solvent using $\mathrm{NaOH}(0.6 \mathrm{~g})$ and chlorobutanol $(1.5 \mathrm{~mL}, 2.5 \mathrm{~mL}, 3.5 \mathrm{~mL})$ with corn starch $(10 \mathrm{~g})$ at $50{ }^{\circ} \mathrm{C}$ for $20 \mathrm{~h}$; ${ }^{[b]}$ the mass of $\delta$-hydroxybutyl starch ether; ${ }^{[c]}$ the peak area ratios of $A_{C 4 H 9 I} / A_{\text {Toluene; }}{ }^{[d]}$ the measured value of $m_{C 4 H 9 I}$ by using the equation of calibration curve (2); ${ }^{[\mathrm{e}]}$ using the equation of calibration curve (1).

\subsection{Characterisation}

\subsubsection{FTIR Spectroscopy}

A typical FTIR spectrum of $\delta$-HBS is shown in Figure 6, Figures S1 and S2, together with a spectrum of unmodified corn starch. In comparison with unmodified corn starch, the difference between $\delta$-HBS and the starch spectrum was conspicuous. The IR spectrum of $\delta$-HBS showed the distinct absorption bands that appeared at $3394 \mathrm{~cm}^{-1}$, which was assigned to stretching vibration of $-\mathrm{OH}$. The absorption bands became narrower and shifted to higher wavenumbers. The weak peak toward $2929 \mathrm{~cm}^{-1}$ was attributed to the $\mathrm{C}-\mathrm{H}$ asymmetric stretching vibration. The high density of $-\mathrm{CH}_{2}$ groups was in the $\delta$-HBS polymer structure. A large quantity of $-\mathrm{CH}_{2}$ groups was fetched into $\mathrm{HBS}$ by etherification, and the peak of the $\delta$-HBS with higher MS at $1417 \mathrm{~cm}^{-1}$ which was corresponding to bending vibration of $-\mathrm{CH}_{2}$ showed significant change. The absorption peak of the $\mathrm{C}-\mathrm{O}$ 
stretching of the ether group was observed at $1157 \mathrm{~cm}^{-1}$, as shown in Figure 6. In addition, the absorption peak of C-O-C glycosidic bonds of AGU of starch molecules at $860 \mathrm{~cm}^{-1}$ was observed to remain intact, suggesting that the aforementioned molecules were not degraded after etherification. Therefore, the results of FTIR spectra further proved that $\delta$-HBS was synthesised.

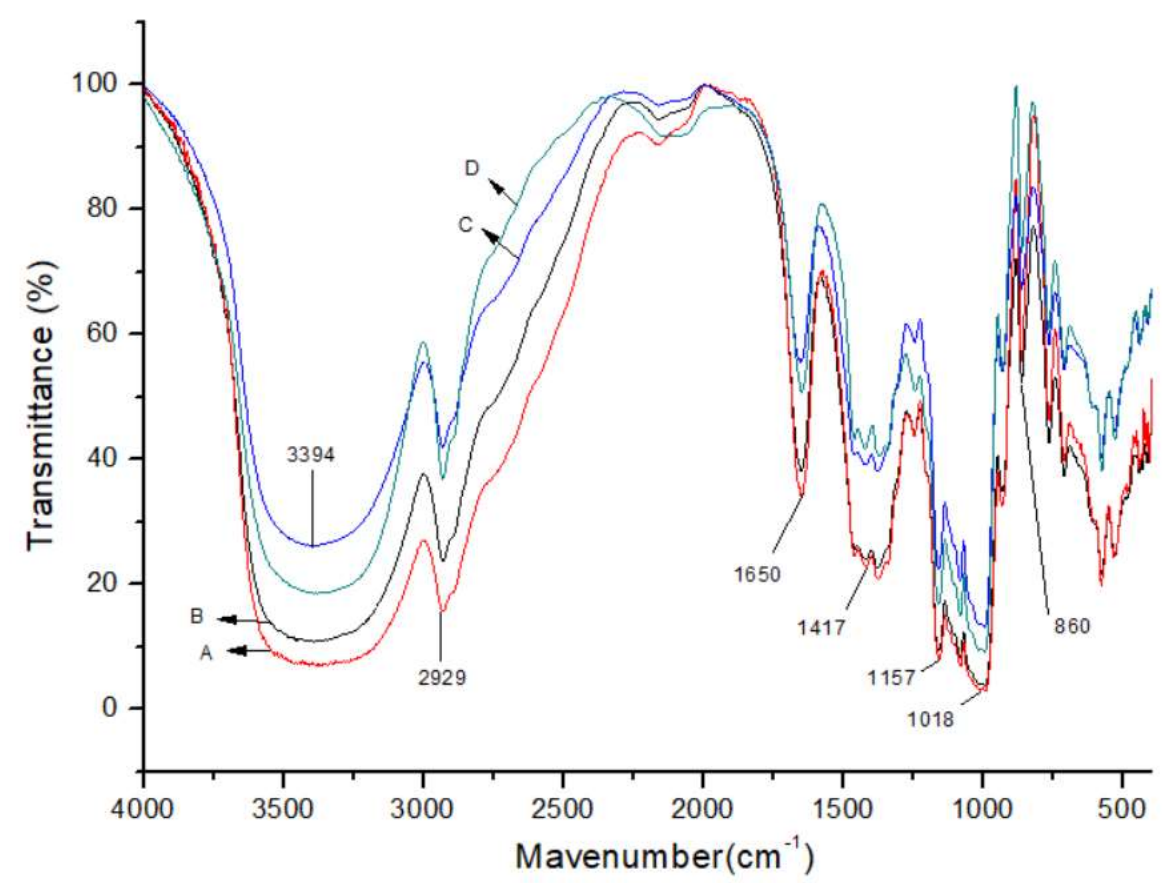

Figure 6. FTIR spectra of $\delta$-HBS at (D) MS $=0.12$, (C) MS $=0.076$, (B) $\mathrm{MS}=0.042$, and (A) unmodified starch.

\subsubsection{NMR Spectroscopy}

A typical ${ }^{1} \mathrm{H}$ NMR spectrum of 8 -HBS is shown in Figure 7 , together with a spectrum of unmodified corn starch. The ${ }^{1} \mathrm{H}$ NMR spectral signals between 3.4 and $4.1 \mathrm{ppm}$ (Figure 7A) corresponded to the six protons of the constituent repeating $\alpha$-D-glucopyranosyl units (AGUs) of unmodified starch, except for the proton of acetal $(\mathrm{O}-\mathrm{C}(\mathrm{H})-\mathrm{O})$ observed as a singlet at $5.4 \mathrm{ppm}$. Figure 7B-D show the peaks between 3.2 and 3.8 were assigned to the six protons of the AGUs and the four protons of $\mathrm{O}-\mathrm{CH}_{2}$ - group from the $\mathrm{O}-\mathrm{CH}_{2}-\mathrm{CH}_{2}-\mathrm{CH}_{2}-$ $\mathrm{CH}_{2}-\mathrm{OH}$ group of the substituent. Owing to the introduction of $\mathrm{OCH}_{2} \mathrm{CH}_{2} \mathrm{CH}_{2} \mathrm{CH}_{2} \mathrm{OH}$, the characteristic peak of the proton of acetal $(\mathrm{O}-\mathrm{C}(\mathrm{H})-\mathrm{O})$ was shifted and split, resulting in a multiple-peak separation between 5.1 and $5.5 \mathrm{ppm}$. The clear broadening of anomeric proton's peak for $\delta$-HBS is due to the substitution at the O-2 position $[25,26]$. The presence of a spectral signal at $1.24 \mathrm{ppm}$ (Figure 7B-D) confirmed the presence of four methylene protons of the $\mathrm{C}-\mathrm{CH}_{2}-\mathrm{CH}_{2}-\mathrm{C}$ group in $-\mathrm{OCH}_{2} \mathrm{CH}_{2} \mathrm{CH}_{2} \mathrm{CH}_{2} \mathrm{OH}$. The spectrograms indicated successful etherification. 


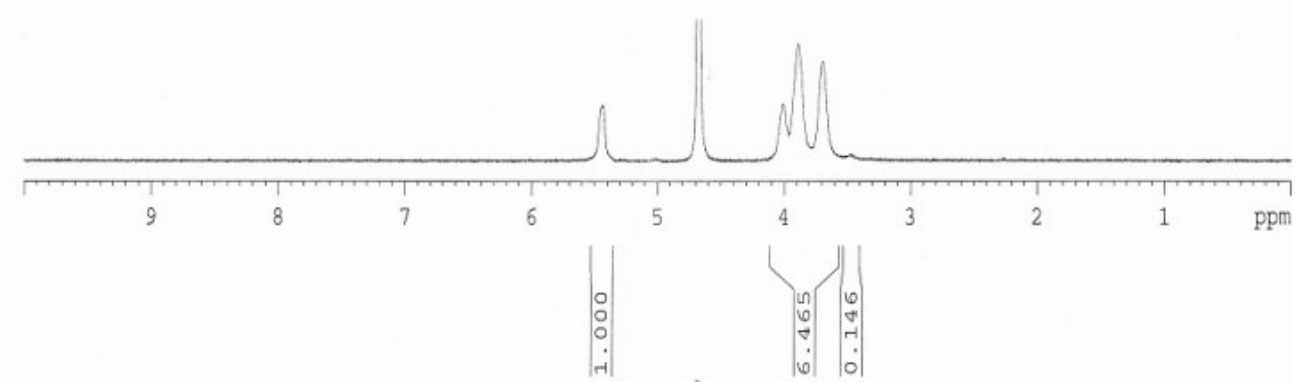

(A)

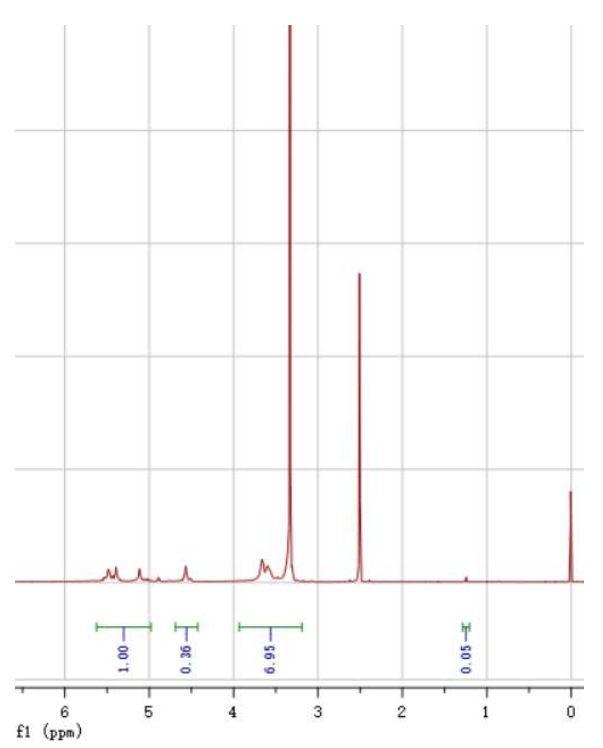

(B)

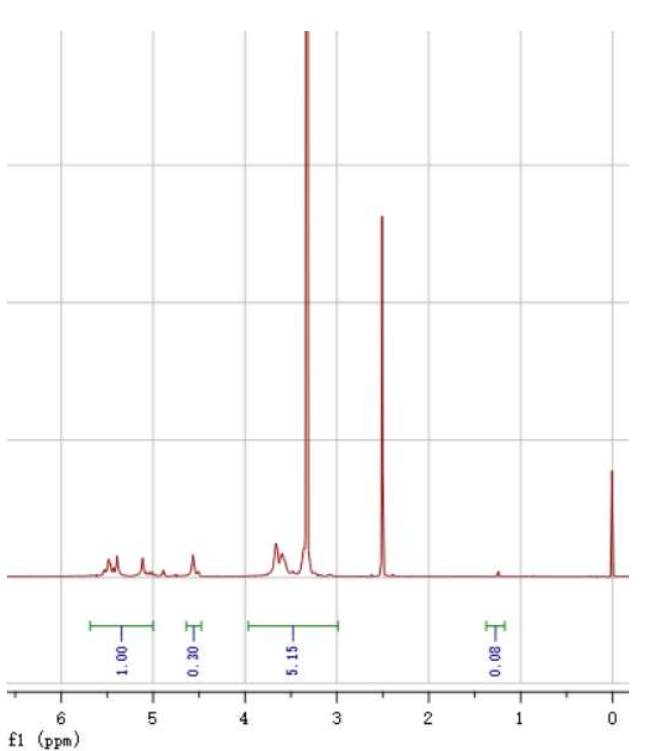

(C)

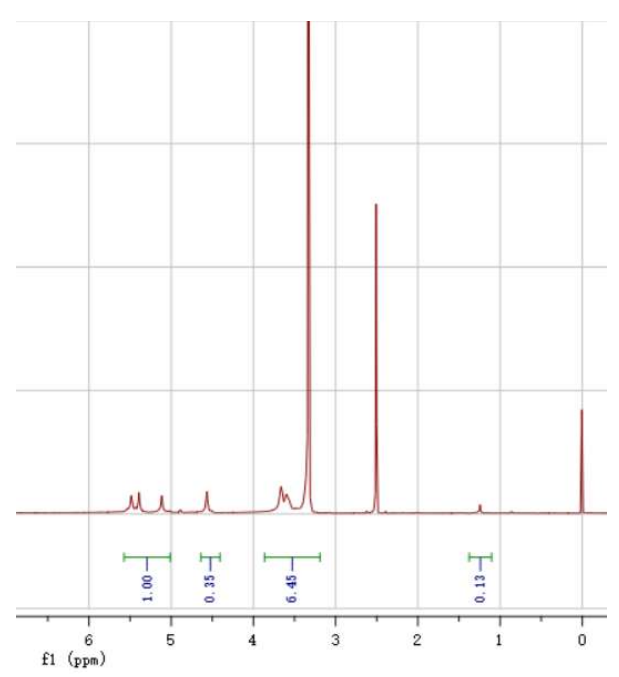

(D)

Figure 7. H-NMR spectra of $\delta$-HBS at (D) MS $=0.12,(\mathbf{C}) \mathrm{MS}=0.076,(\mathbf{B}) \mathrm{MS}=0.042$, and (A) unmodified starch.

\section{Conclusions}

A new class of hydroxybutyl starch was synthesised by utilising 4-chlorobutan-1-ol as the etherifying reagent. Zeisel gas chromatography was adopted for the analysis of the MS of $\delta$-HBS. For consideration of the potentials of a relatively new, cheap, underutilised but abundant starch resource, further investigations are currently underway in our laboratory. 
Supplementary Materials: The following are available online. Supplementary data contains the following information: Synthesis of $\delta$-HBS (Scheme S1), characterizations of $\delta$-HBS using FTIR and ${ }^{1}$ H NMR (Figures S1 and S2), precision determination (Table S1), gas chromatograms (Figures S3-S6).

Author Contributions: Conceptualization, X.-L.M. and X.-L.L.; formal analysis, X.-L.M. and J.C.; investigation, W.-K.P.; writing-original draft preparation, X.-L.M. and X.-L.L.; and writing-review and editing, X.-L.L.; funding acquisition, X.-L.L. All authors have read and agreed to the published version of the manuscript.

Funding: This work was supported by the Scientific Research Start Foundation Project of Chuzhou University (2017qd15) and the University Natural Science Research Project of Anhui Province (KJ2018B15), Post-doctoral Program of Anhui Province (2020B406).

Institutional Review Board Statement: Not applicable.

Informed Consent Statement: Not applicable.

Data Availability Statement: Not applicable.

Conflicts of Interest: The authors declare that they have no competing interests.

Sample Availability: Samples of the compounds are available from the authors.

\section{References}

1. Fu, Z.; Zhang, L.; Ren, M.H.; BeMiller, J.N. Developments in Hydroxypropylation of Starch: A Review. Starch 2019, 71, 1800167. [CrossRef]

2. Botha, C.; Viktor, Z.; Moire, C.; Farcet, C.; Brothier, F.; Pfukwa, H.; Pasch, H. Separation of hydrophobically modified hyaluronic acid according to the degree of substitution by gradient elution high performance liquid chromatography. Anal. Bioanal. Chem. 2018, 410, 4259-4273. [CrossRef]

3. Wang, Y.W.; Li, A.M.; Yang, H. Effects of substitution degree and molecular weight of carboxymethyl starch on its scale inhibition. Desalination 2017, 408, 60-69. [CrossRef]

4. Bellmann, R.; Feistritzer, C.; Wiedermann, C.J. Effect of Molecular Weight and Substitution on Tissue Uptake of Hydroxyethyl Starch. Clin. Pharmacokinet. 2012, 51, 225-236. [CrossRef]

5. Kaur, B.; Ariffin, F.; Bhat, R.; Karim, A.A. Progress in starch modification in the last decade. Food Hydrocolloid. 2012, 26, 398-404. [CrossRef]

6. Zhang, G.X.; She, Y.; You, Y.Q.; Yan, L.X.; Shi, B. The application of an advanced visualized method in synthesis process optimization of carboxymethyl hydroxyethyl starch. Carbohydr. Polym. 2012, 79, 673-676. [CrossRef]

7. Lee, Y.C.; Baaske, D.M.; Carter, J.E. Determination of the molar substitution ratio of hydroxyethyl starches by gas chromatography. Anal. Chem. 1983, 55, 334-338. [CrossRef]

8. Tai, H.; Powers, R.M.; Protzman, T.F. Determination of Hydroxyethyl Group in Hydroxyethyl Starch by Pyrolysis-Gas Chromatographic Technique. Anal. Chem. 1964, 36, 108-110. [CrossRef]

9. Lortz, H.J. Determination of Hydroxyalkyl Groups in Low-Substituted Starch Ethers. Anal. Chem. 1956, 28, 892-895. [CrossRef]

10. Cobler, J.G.; Samsel, E.P.; Beaver, G.H. Determination of alklyl cellulose ethers by gas chromatography. Talanta 1962, 9, $473-481$. [CrossRef]

11. Hodges, K.L.; Kester, W.E.; Wiederrich, D.L.; Grover, J.A. Determination of alkoxyl substitution in cellulose ethers by Zeisel gas chromatography. Anal. Chem. 1979, 51, 2172-2176. [CrossRef]

12. Johnson, D.P. Spectrophotometric determination of the hydroxypropyl group in starch ethers. Anal. Chem. 1969, 41, 859-860. [CrossRef]

13. Chun, E.H.; Oh, S.M.; Kim, H.Y.; Kim, B.Y.; Baik, M.Y. Effect of high hydrostatic pressure treatment on conventional hydroxypropylation of maize starch. Carbohydr. Polym. 2016, 146, 328-336. [CrossRef] [PubMed]

14. Harry-O'Kuru, R.E.; Moser, K.B.; Gordon, S.H. Colorimetric determination of the molar substitution of 2-hydroxybutyl and related starch ethers. Carbohydr. Polym. 1992, 17, 313-318. [CrossRef]

15. Wokadala, O.C.; Emmambux, N.M.; Ray, S.S. Inducing PLA/starch compatibility through butyl-etherification of waxy and high amylose starch. Carbohydr. Polym. 2014, 112, 216-224. [CrossRef] [PubMed]

16. Zhang, B.S.; Yu, H.; Wang, J.P.; Qu, Z.H. Effects of the degree of substitution (DS) during hydroxybutylation on the physicochemical characteristics of maize starch. Mod. Food Sci. Technol. 2014, 30, 85-91.

17. Dong, S.T.; Li, S.; Hao, Y.C.; Gao, Q.Y. Hydroxybutyl starch-based thermosensitive hydrogel for protein separation. Int. J. Biol. Macromol. 2019, 134, 165-171. [CrossRef]

18. Zheng, B.W.; Karski, M.; Taylor, S.D. Thermoresponsive hydroxybutylated starch nanoparticles. Carbohydr. Polym. 2019, 209, 145-151. [CrossRef] [PubMed]

19. Liu, X.L.; Zhang, K.; Hu, Y.; Zhang, Z.J.; Chen, J.; Ma, T.L.; Wang, J.J. Determination of Molar Substitution of $\gamma$-Hydroxypropyl Starch. Starch 2020, 73, 2000013. [CrossRef] 
20. Jones, L.R.; Riddick, J.A. Colorimetric Determination of 1,2-Propanediol and Related Compounds. Anal. Chem. 1957, 29, 1214-1216. [CrossRef]

21. Morgan, P.W. Determination of Ethers and Esters of Ethylene Glycol. A Modified Alkoxyl Analysis. Ind. Eng. Chem. Anal. Ed. 1946, 18, 500-504. [CrossRef]

22. Chuenkamol, B.; Puttanlek, C.; Rungsardthong, V.; Uttapap, D. Characterization of low-substituted hydroxypropylated canna starch. Food Hydrocolloid. 2007, 21, 1123-1132. [CrossRef]

23. Lawal, O.S.; Ogundiran, O.O.; Adesogan, E.K.; Ogunsanwo, B.M.; Sosanwo, O.A. Effect of Hydroxypropylation on the Properties of White Yam (Dioscorea rotundata) Starch. Starch 2008, 60, 340-348. [CrossRef]

24. Lawal, O.S. Hydroxypropylation of pigeon pea (Cajanus cajan) starch: Preparation, functional characterizations and enzymatic digestibility. Lwt-Food Sci. Technol. 2011, 44, 771-778. [CrossRef]

25. Gan, L.X.; Xu, A.S.; Seib, P.A. Syntheses of Methyl 2-O-, 3-O- and 6-O-(2'-Hydroxypropyl)- $\alpha$-D-Glucopyranosides. J. Carbohydr. Chem. 1997, 16, 155-164. [CrossRef]

26. Ju, B.Z.; Yan, D.M.; Zhang, S.F. Micelles self-assembled from thermoresponsive 2-hydroxy-3-butoxypropyl starches for drug delivery. Carbohydr. Polym. 2012, 87, 1404-1409. [CrossRef] 